\title{
Efficacy of ustekinumab against infliximab-induced psoriasis and arthritis associated with Crohn's disease
}

\section{Satohiro Matsumoto \\ Hirosato Mashima}

Department of Gastroenterology, Saitama Medical Center, Jichi Medical University, Saitama, Japan
Correspondence: Satohiro Matsumoto Department of Gastroenterology, Saitama Medical Center, Jichi Medical University, I-847 Amanuma, Omiya, Saitama 330-8503, Japan

Tel +8 I 486472 III

Fax +8I 486485188

Email s.w.himananon@ac.auone-net.jp
This article was published in the following Dove Press journal: Biologics:Targets and Therapy

\begin{abstract}
Anti-TNF $\alpha$ drugs have been shown to be effective for maintaining stable remission in patients with Crohn's disease. However, some problems have been identified during clinical use of this class of drugs, such as secondary treatment failure, in which the drugs become progressively less effective with time, and the development of paradoxical reactions such as psoriatic skin symptoms. Thus, while anti-TNF $\alpha$ drugs are used to treat psoriasis, they can sometimes also cause paradoxical psoriasis, characterized by the appearance of psoriasis-like eruptions, which has recently begun to attract attention. Furthermore, inflammatory bowel disease is not only associated with intestinal lesions, but also with a variety of extraintestinal manifestations, of which arthritis is relatively common. We encountered a case of Crohn's disease with arthritis, as an extraintestinal manifestation, and paradoxical psoriasis caused by infliximab treatment, in which ustekinumab proved extremely effective, not only for alleviating the arthritis, but also against the skin manifestations. To the best of our knowledge, this is the first reported case of the efficacy of ustekinumab against paradoxical psoriasis and arthritis in a patient with Crohn's disease.
\end{abstract}

Keywords: ustekinumab, paradoxical psoriasis, infliximab, arthritis, Crohn's disease

\section{Introduction}

The advent of TNF $\alpha$ inhibitor drugs has greatly changed the standard treatment for inflammatory bowel disease (IBD). Treatment with anti-TNF $\alpha$ drugs has been shown to allow maintained stable remission in patients with Crohn's disease. Furthermore, higher therapeutic goals beyond clinical remission alone, such as mucosal healing and deep remission, have also been pursued. However, some problems associated with the use of anti-TNF $\alpha$ drugs have been identified, such as the onset of secondary failure, in which the drugs become progressively less effective with time, ${ }^{1-3}$ and the occurrence of paradoxical skin reactions, eg, psoriatic manifestations. ${ }^{4,5}$

In regard to the development of paradoxical skin reactions, development of eczemalike and psoriasiform eruptions has been reported during treatment with anti-TNF $\alpha$ drugs. ${ }^{6}$ Thus, while these drugs have, in fact, been used to treat psoriasis, some patients can also paradoxically develop psoriasis-like eruptions during treatment; this condition has recently attracted attention. ${ }^{7}$ Wollina et al reported that $\sim 40 \%$ of patients with skin eruptions in their case series could continue to receive treatment with the anti-TNF $\alpha$ agent in combination with topical agents for control of the paradoxical psoriatic lesions, and that symptomatic remission or improvement of the skin lesions was obtained in all cases. They contended that it is not necessary to discontinue administration of the anti-TNF $\alpha$ drugs in patients with paradoxical skin reactions. ${ }^{8}$ Therapeutic strategies 
for paradoxical psoriasis caused by anti-TNF $\alpha$ drugs should be selected taking into consideration the extent of the skin symptoms and severity of the primary disease.

\section{Ethical considerations}

Written informed consent was obtained from the patient for publication of this case report and the accompanying images.

\section{Case report}

A 54-year-old Japanese man diagnosed with Crohn's disease, with lesions in the small intestine and colon, had been started infliximab treatment 3 years earlier. Two years after the start of treatment, he presented with palmoplantar pustulosis-like eruptions involving the palms of the hands and soles of the feet of both sides, followed by the appearance of scaly eruptions all over the body (Figure 1). Lower gastrointestinal endoscopy revealed that the lower ileal and colonic lesions were in remission. The Clinical Disease Activity Index (CDAI) was 25, and the serum CRP level was $0.25 \mathrm{mg} / \mathrm{dL}$. The patient was referred to the dermatology department, where he was diagnosed with paradoxical psoriasis associated with infliximab use (Psoriasis Area Severity Index [PASI] 14.3), and treatment was started with a topical steroid and vitamin $\mathrm{D}_{3}$ ointment. However, because of the poor response of the skin lesions to this treatment, infliximab was discontinued 3 months after the diagnosis of paradoxical psoriasis. However, the skin symptoms, while showing a tendency to abate, nevertheless persisted, with a PASI of 9.3. There was no relapse of the gastrointestinal symptoms. Eight months after the discontinuation of infliximab, the patient developed painful knee joint swelling (Figure 2A). The gastrointestinal symptoms still remained in remission. The CDAI was 122 and the serum CRP level was $0.67 \mathrm{mg} / \mathrm{dL}$. Plain radiographs of the right knee revealed no abnormal findings. Although arthrocentesis was performed, no significant abnormalities were detected in the synovial fluid. Based on these findings, we diagnosed the patient with peripheral arthritis as an extraintestinal manifestation of Crohn's disease. Because the skin symptoms persisted, the patient was started on treatment with ustekinumab. Soon after the start of this treatment, the

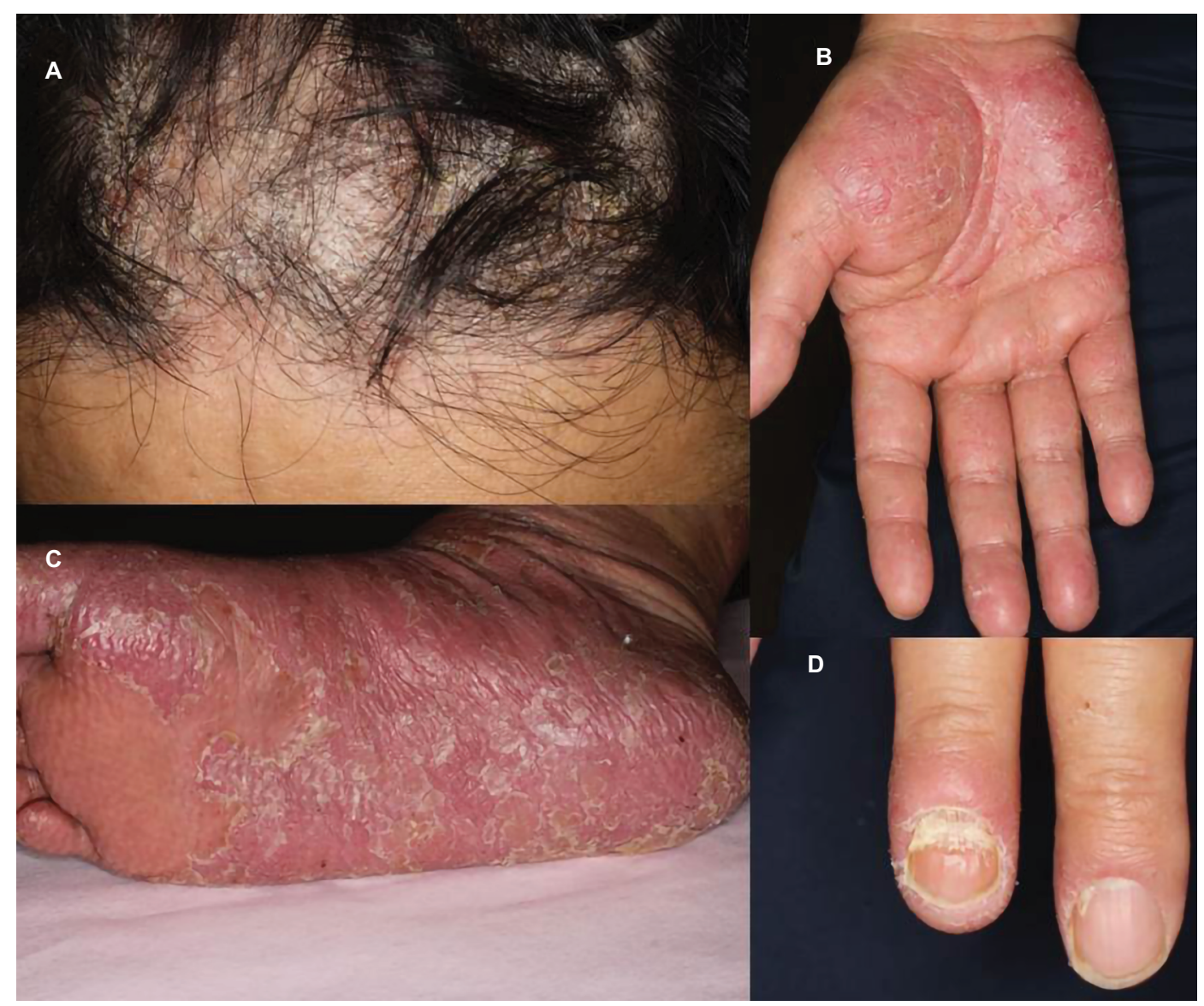

Figure I Psoriasiform skin lesions in the frontal scalp region (A), palms (B), soles (C), and fingernails (D). 
arthritis abated (Figure 2B), and within 2 months, the skin symptoms also resolved (PASI 0.8) (Figure 3). While the patient continues to receive ustekinumab every 3 months, there has been no relapse of any of the gastrointestinal, skin, or joint symptoms.

\section{Discussion}

Tillack et al reported that anti-TNF $\alpha$ drugs caused psoriasiform skin lesions in $4.8 \%$ of 434 patients with IBD receiving treatment with this class of drugs. ${ }^{4}$ Pugliese et al reported that among 839 patients with IBD treated by them with anti-TNF $\alpha$ drugs, the incidence of paradoxical psoriasis was five per 100 person-years. ${ }^{5}$ Both the aforementioned studies identified smoking as a risk factor for paradoxical psoriasis; in addition, the latter study also showed that concomitant use of immunomodulators reduced the risk of development of psoriasis associated with anti-TNF $\alpha$ drug treatment., In regard to the treatment of paradoxical psoriasis, in one study, remission was achieved in $64 \%$ of patients with topical treatment alone, with no need for any additional treatment or discontinuation of the anti-TNF $\alpha$ drugs. ${ }^{5}$ Ustekinumab was only utilized for patients who failed to respond to different anti-TNF $\alpha$ drugs or topically applied agents, and improvement was noted in all of these patients. ${ }^{4}$

In addition to the characteristic intestinal lesions, IBD is also known to be associated with various extraintestinal manifestations. The reported incidence of extraintestinal manifestations in patients with Crohn's disease ranges from

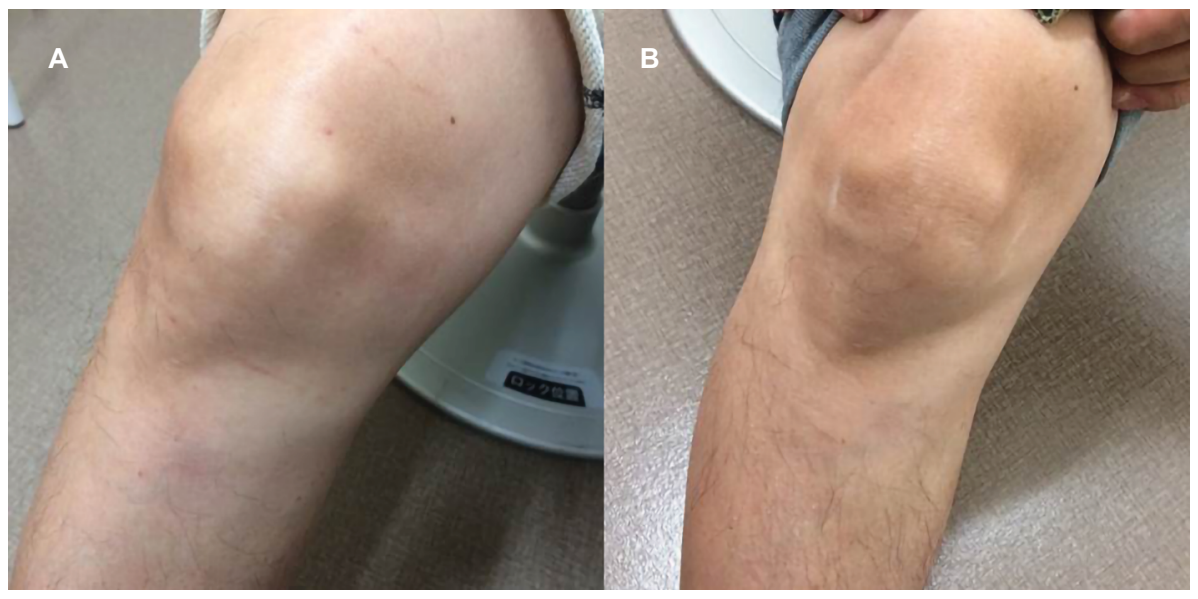

Figure 2 Swelling in the right knee joint (A) and complete healing of the lesion after therapy with ustekinumab (B).

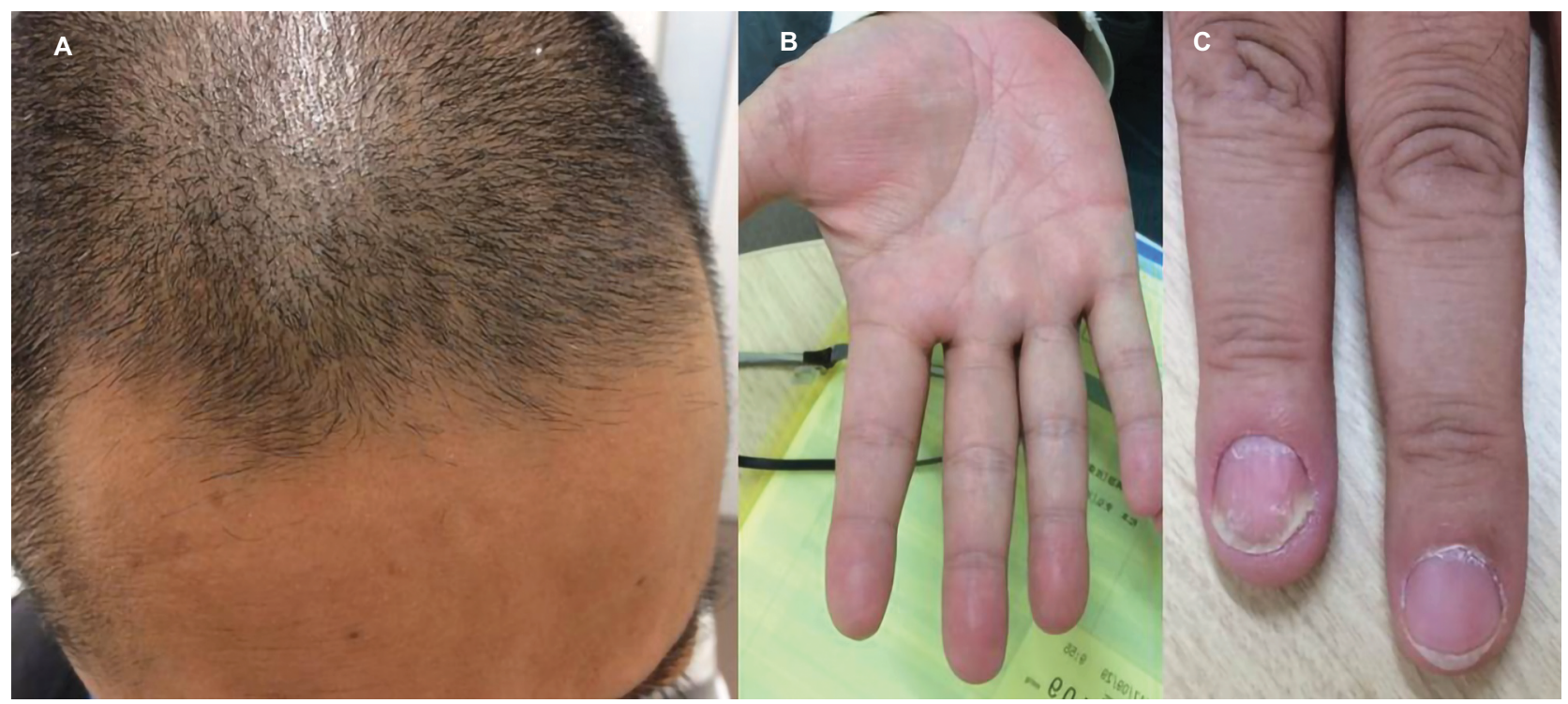

Figure 3 Complete healing after one injection of ustekinumab in the frontal scalp region (A), palms (B), and fingernails (C). 
$25 \%$ to $46 \%{ }^{9,10}$ In regard to the concomitant arthritis in our patient, peripheral arthritis coexists in $8 \%$ of patients with Crohn's disease, ${ }^{11}$ and IBD accounts for $3.4 \%$ of the comorbidities associated with peripheral spondyloarthritis. ${ }^{12}$ Peripheral arthritis in patients with Crohn's disease manifests as oligoarthritis, defined as involvement of less than five joints (accounting for $65 \%$ of all cases) or monarthritis (accounting for 27\% of all cases). Oligoarthritis commonly affects the knee and foot joints, but does not, in general, destroy bone. ${ }^{12}$

Anti-TNF $\alpha$ drugs have been shown to be highly effective for the treatment of IBD, and their introduction has greatly changed the standard therapeutic strategies for IBD. However, these drugs have been shown to be not adequately effective in some cases, and ustekinumab is attracting attention as one of the second- or subsequent-line drugs in such patients. Ustekinumab is a human monoclonal antibody directed against the shared p40 subunit of IL-12 and IL-23, and is considered to exert its anti-inflammatory effects by inhibiting these ILs and their downstream proinflammatory cytokines, namely, IFN- $\gamma$ and IL-17. In a Phase II clinical study conducted in patients with Crohn's disease, this drug was demonstrated to be clinically effective in patients showing inadequate response to anti-TNF $\alpha$ drugs. ${ }^{13}$ Furthermore, ustekinumab has also been shown to be effective and safe in patients with moderate-to-severe psoriasis. ${ }^{14,15}$ It has been reported that use of ustekinumab is not associated with a higher risk of serious infections than other biologics. ${ }^{16}$ Long-term data from randomized controlled trials conducted to evaluate the tolerance to ustekinumab in patients with psoriasis revealed that use of the drug was not associated with any increase in the risk of death, severe infection or malignancy. ${ }^{17}$ In our case, ustekinumab appears to have been effective against both the paradoxical psoriasis caused by infliximab treatment and the arthritis occurring as an extraintestinal manifestation of Crohn's disease. In psoriasis induced by anti-TNF $\alpha$ drugs, it is assumed that inhibition of TNF $\alpha$ by the anti-TNF $\alpha$ drug enhances IFN- $\gamma$ production, which is not regulated by plasmacytoid dendritic cells, resulting in recruitment of $\mathrm{T}$ cells and secretion of the proinflammatory cytokines IL-12 and IL-23. 4,18,19

\section{Conclusion}

We encountered a case of Crohn's disease, in which ustekinumab was effective in controlling paradoxical psoriasis that developed during infliximab treatment and also alleviated the arthritis as an extraintestinal manifestation in a patient with Crohn's disease. Thus, ustekinumab is expected to be not only effective against Crohn's enteritis, but also against paradoxical reactions to anti-TNF $\alpha$ drugs and extraintestinal manifestations of Crohn's disease.

\section{Disclosure}

The authors report no conflicts of interest in this work.

\section{References}

1. Gisbert JP, Panés J. Loss of response and requirement of infliximab dose intensification in Crohn's disease: a review. Am J Gastroenterol. 2009;104(3):760-767.

2. Billioud V, Sandborn WJ, Peyrin-Biroulet L. Loss of response and need for adalimumab dose intensification in Crohn's disease: a systematic review. Am J Gastroenterol. 2011;106(4):674-684.

3. Otake H, Matsumoto S, Mashima H. Does long-term efficacy differ between infliximab and adalimumab after 1 year of continuous administration?: A STROBE-compliant retrospective cohort study. Medicine. 2017;96(16):e6635.

4. Tillack C, Ehmann LM, Friedrich M, et al. Anti-TNF antibody-induced psoriasiform skin lesions in patients with inflammatory bowel disease are characterised by interferon- $\gamma$-expressing Th1 cells and IL-17A/ IL-22-expressing Th17 cells and respond to anti-IL-12/IL-23 antibody treatment. Gut. 2014;63(4):567-577.

5. Pugliese D, Guidi L, Ferraro PM, et al. Paradoxical psoriasis in a large cohort of patients with inflammatory bowel disease receiving treatment with anti-TNF alpha: 5-year follow-up study. Aliment Pharmacol Ther. 2015;42(7):880-888.

6. Rahier JF, Buche S, Peyrin-Biroulet L, et al. Severe skin lesions cause patients with inflammatory bowel disease to discontinue anti-tumor necrosis factor therapy. Clin Gastroenterol Hepatol. 2010;8(12):1048-1055.

7. Ramos-Casals M, Brito-Zerón P, Muñoz S, et al. Autoimmune diseases induced by TNF-targeted therapies: analysis of 233 cases. Medicine. 2007;86(4):242-251.

8. Wollina U, Hansel G, Koch A, Schönlebe J, Köstler E, Haroske G. Tumor necrosis factor-alpha inhibitor-induced psoriasis or psoriasiform exanthemata: first 120 cases from the literature including a series of six new patients. Am J Clin Dermatol. 2008;9(1):1-14.

9. Ephgrave K. Extra-intestinal manifestations of Crohn's disease. Surg Clin North Am. 2007;87(3):673-680.

10. Shorbagi A, Bayraktar Y. Primary sclerosing cholangitis--what is the difference between east and west? World J Gastroenterol. 2008;14(25):3974-3981.

11. Malaty HM, Lo GH, Hou JK. Characterization and prevalence of spondyloarthritis and peripheral arthritis among patients with inflammatory bowel disease. Clin Exp Gastroenterol. 2017;10:259-263.

12. Rudwaleit M, van der Heijde D, Landewé R, et al. The Assessment of SpondyloArthritis International Society classification criteria for peripheral spondyloarthritis and for spondyloarthritis in general. Ann Rheum Dis. 2011;70(1):25-31.

13. Sandborn WJ, Gasink C, Gao LL, et al. Ustekinumab induction and maintenance therapy in refractory Crohn's disease. $N$ Engl J Med. 2012;367(16):1519-1528.

14. Leonardi CL, Kimball AB, Papp KA, et al. Efficacy and safety of ustekinumab, a human interleukin-12/23 monoclonal antibody, in patients with psoriasis: 76-week results from a randomised, double-blind, placebocontrolled trial (PHOENIX 1). Lancet. 2008;371(9625):1665-1674.

15. Papp KA, Langley RG, Lebwohl M, et al. Efficacy and safety of ustekinumab, a human interleukin-12/23 monoclonal antibody, in patients with psoriasis: 52-week results from a randomised, double-blind, placebocontrolled trial (PHOENIX 2). Lancet. 2008;371(9625):1675-1684.

16. Wheat CL, Ko CW, Clark-Snustad K, Grembowski D, Thornton TA, Devine B. Inflammatory Bowel Disease (IBD) pharmacotherapy and the risk of serious infection: a systematic review and network metaanalysis. BMC Gastroenterol. 2017;17(1):52. 
17. Papp KA, Griffiths CE, Gordon K, et al. Long-term safety of ustekinumab in patients with moderate-to-severe psoriasis: final results from 5 years of follow-up. Br J Dermatol. 2013;168(4):844-854.

18. Fiorino G, Danese S, Pariente B, Allez M. Paradoxical immune-mediated inflammation in inflammatory bowel disease patients receiving antiTNF- $\alpha$ agents. Autoimmun Rev. 2014;13(1):15-19.
19. Moran GW, Lim AW, Bailey JL, et al. Review article: dermatological complications of immunosuppressive and anti-TNF therapy in inflammatory bowel disease. Aliment Pharmacol Ther. 2013;38(9): 1002-1024.

\section{Publish your work in this journal}

Biologics: Targets and Therapy is an international, peer-reviewed journal focusing on the patho-physiological rationale for and clinical application of Biologic agents in the management of autoimmune diseases, cancers or other pathologies where a molecular target can be identified. This journal is indexed on PubMed Central, EMBase, and Scopus.
Dovepress

The manuscript management system is completely online and includes a very quick and fair peer-review system, which is all easy to use. Visit http://www.dovepress.com/testimonials.php to read real quotes from published authors.

Submit your manuscript here: https://www.dovepress.com/biologics-targets-and-therapy-journal 